\title{
FT-IR and XRD analysis of coal from Makum coalfield of Assam
}

\author{
Binoy K SAIKIA ${ }^{1, *}, \mathrm{R}$ K Boruah ${ }^{2}$ and P K Gogoi ${ }^{3}$ \\ ${ }^{1}$ Department of Chemical Sciences, Tezpur University, Napaam, Tezpur 784 028, India. \\ ${ }^{2}$ Analytical Chemistry Division, Regional Research Laboratory (CSIR), Jorhat 785 006, India. \\ ${ }^{3}$ Department of Chemistry, Dibrugarh University, Dibrugarh 786 004, India. \\ *e-mail: binoyrrl@yahoo.com
}

High sulphur coal sample from Ledo colliery of Makum coalfield, Assam, India was studied using FT-IR and XRD methods. FT-IR study shows the presence of aliphatic $-\mathrm{CH},-\mathrm{CH}_{2}$ and $-\mathrm{CH}_{3}$ groups, aliphatic $\mathrm{C}-\mathrm{O}-\mathrm{C}$ stretching associated with $-\mathrm{OH}$ and $-\mathrm{NH}$ stretching vibrations and $\mathrm{HCC}$ rocking (single and condensed rings). XRD pattern of the coal shows that it is amorphous in nature. Function of Radial Distribution Analysis (FRDA) indicates that coal is lignite in type and there is no evidence of graphite-like structure. The first maximum in the G $(r)$ plot of FRDA at $r=0.14 \mathrm{~nm}$ relates to the aliphatic $\mathrm{C}-\mathrm{C}$ bond (Type $\mathrm{C}-\mathrm{CH}=\mathrm{CH}-\mathrm{C}$ ), the second maximum at $r=0.25 \mathrm{~nm}$ relates to the distance between carbon atoms of aliphatic chains that are located across one carbon atom. The curve intensity profiles obtained from FRDA show quite regular molecular packets for this coal. The coal was found to be lignite in nature.

\section{Introduction}

Coal is heterogeneous. It consists primarily of organic materials admixed with mineral matter including sulphur. The organic material in the coal that is derived through the process of coalification is essentially composed of large polymeric molecules in which chemical structures are variable and non-repetitive. However, the properties of coal appear to depend mainly on the physical and chemical structure of these organic compounds. The mineral matter may occur both as mineral species and as mineral phases of widely-varying particle sizes and also as species that are chemically complexed by the organic matter. It is believed that the physical structure of coal is represented by spatial arrangement of large complex molecules, along with a few much smaller ones. The same appears to be the case with products obtained from physical processing of coal. The physical as well as chemical properties of coal depend upon its physical structure, and the physical structure of coal may be studied without going into details of its chemical structure.

Chemical structures of the organic molecule in coal vary greatly, particularly with its rank, to the extent that coals even from the same region might show more differences than similarities. Physical properties of coal generally vary so systematically with coal rank that it might be possible to reasonably predict the carbon content of the volatile matter of the coal. In the northeastern part of India, the coalfields of Arunachal Pradesh, Assam and Nagaland are disposed along a linear belt of overthrust, known as the 'belt of Schuppen', where tertiary strata have been folded and dispersed into a number of thrust slices (Misra 1992). The chemical properties of these coals show characteristics of both low (on volatile matter content) and high (on moisture and calorific value) ranks. The coals have a low softening temperature and a high swelling index, volatile matter, hydrogen and sulphur contents besides having the highest tar yield among the Indian coals.

Keywords. Ledo coal; lignite; graphite-like structure. 


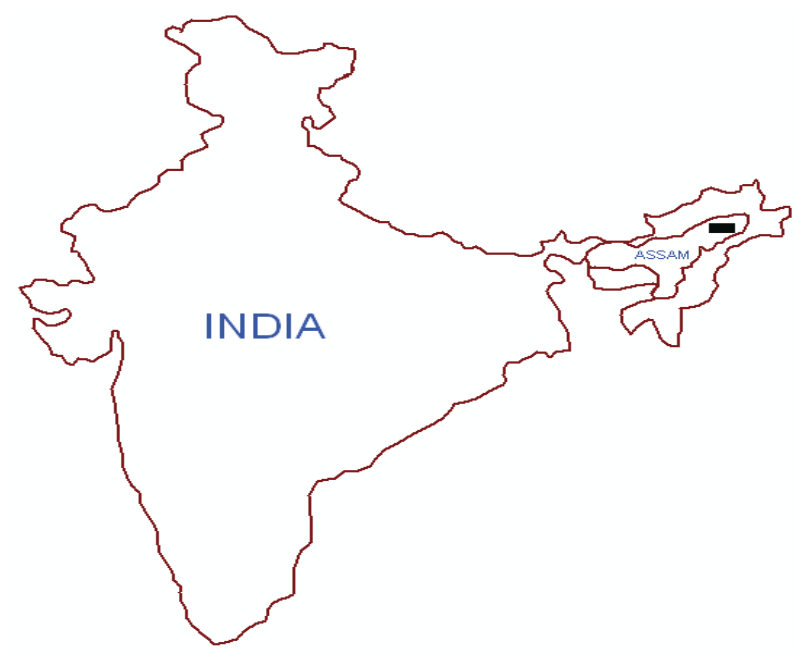

Figure 1. The operating area of Makum coalfield (marked) in Assam, India (not to scale).

\subsection{Assam coal and present work}

Assam coals have been classified as the subbituminous type on the basis of studies on their chemical composition and physical characteristics. These are high sulphur coals with a total reserve of about 260 million tonnes. Because of its sulphur content, it has to be blended with other auxiliary fuels, such as natural gas or imported coals to satisfy the coal quality requirement for thermal power generation, particularly from the emission point of view. Since mineral matter affects almost all aspects of coal utilization, the acceptance of coal for industrial application depends critically on both organic and inorganic matter. X-ray diffraction (XRD) and Fourier Transform Infrared (FT-IR) spectroscopy are powerful tools for characterization of coal and its products as they furnish a comprehensive view about the structure/composition of the materials. In the present work, FT-IR and XRD have been used to characterize the inorganic and organic matter of a coal sample collected from Ledo colliery of Makum coalfield in Margherita area of Tinsukia district of Assam (figure 1). The work includes a structural analysis of this coal by Radial Distribution Function methods (RDF) by using the X-ray diffraction intensity data and also the assigning of functional groups present in the coal structure by FT-IR spectroscopy.

\section{Experimental}

The sample was ground to -200 mesh BS before using it for FT-IR, XRD and other analysis. X-ray diffraction data were obtained using computer controlled X-ray Diffractometer Type XPERT PRO

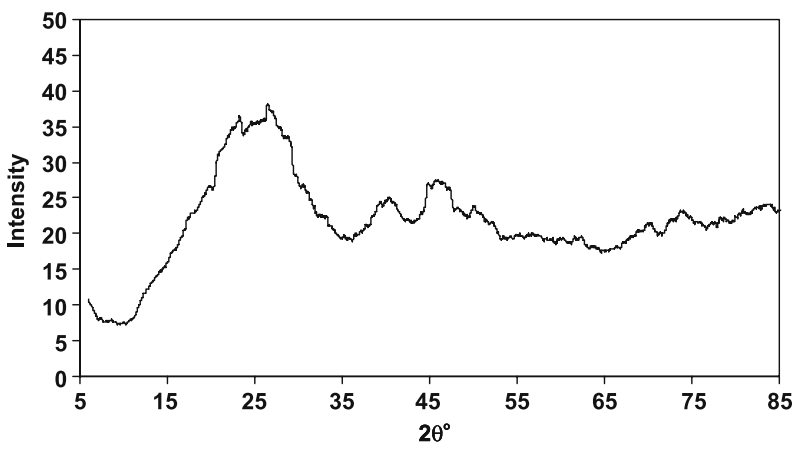

Figure 2. X-ray diffractogram of Ledo coal sample.

(PHILIPS). Operating parameters were as follows: start angle: 3.015, target: $\mathrm{Cu}$ (Fe-filtered), stop angle: 100.0, measuring time: 0.5 and step angle: 0.03 , data processing conditions included: smoothing points, Goniometer radius ( $\mathrm{R}$ ): $240 \mathrm{~mm}$, equatorial angle subtended at the specimen by the detector slit $(\beta)$ : $1^{\circ}$. The observed experimental intensities were corrected for air scatter, absorption and polarization by the sample using the procedure given by Klug and Alexander (1974). The FT-IR spectrum was recorded in FT-IR Spectrophotometer Model 2000 (Perkin Elmer) with KBr pellet. The detector used was deuterated triglycine sulphate (DTGS). The total number of scans were 50 with the spectral resolution of $4 \mathrm{~cm}^{-1}$ during the recording of the spectra.

Proximate analysis of the coal sample was done by standard methods (IS: 1350 (Part I-1984). Perkin Elmer elemental analyzer (model 2400) was used to analyze carbon, hydrogen and nitrogen. Total sulphur was determined by using sulphur determinator (Leco, SC132) and oxygen percentage was calculated by difference. The forms of sulphur were determined by following standard methods (ASTM D 2492). The analysis for the sample was carried out in quadruplicate and mean values have been reported.

\section{Results and discussions}

The XRD pattern (figure 2) of Ledo coal sample shows that it is amorphous in nature. The radial distribution function ( $\mathrm{RDF}=4 \pi r^{2} \rho$ ) and the pair distribution function $\left[\mathrm{G}(r)=4 \pi r^{2}\left(\rho-\rho_{0}\right)\right]$ for a substance consisting of one kind of atom are computed by the methods given elsewhere (Klug and Alexander 1974). The obtained RDF and $\mathrm{G}(r)$ plots for the Ledo coal are shown in figures 4 and 5 . Structural determination based on the Radial Distribution Function fall into two main categories. In the first, the RDF yields the mean distribution of interatomic distances of carbons. In the second category is the determination of structure 


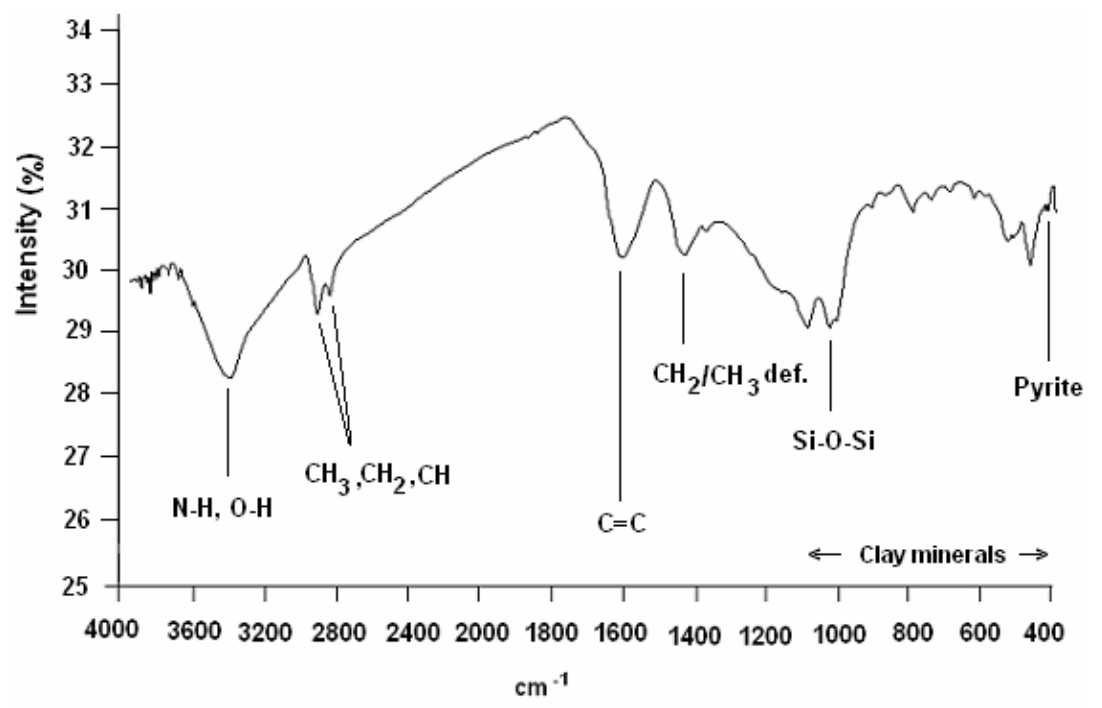

Figure 3. FT-IR spectra of Ledo coal sample.

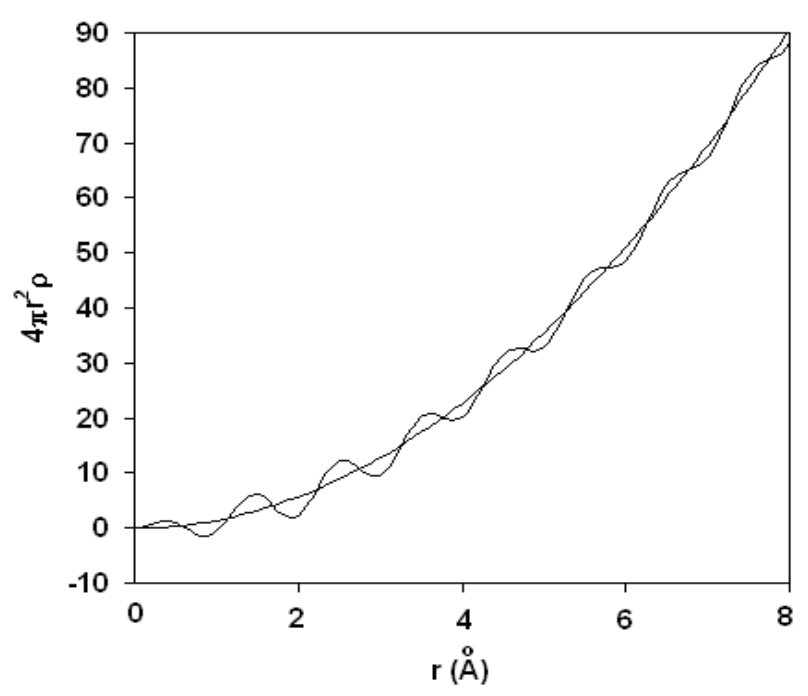

Figure 4. Plot for Radial Distribution Function (RDF) of Ledo coal.

of the coal. In either category, deductions about structure are based on the peak position and areas in the RDF plot. The RDF provides meaningful information about the mean number of nearest neighbours and their mean distances of approaches, and in certain cases intra-molecular configuration may be deduced. Although in the later case configuration of structure is attained by agreement between observed intensity and that calculated on the basis of some model (Kruh 1962).

The RDF distribution curve (figure 4) indicates one nearest neighbour at a distance of about $0.4 \AA$, six second neighbours at about $1.5 \AA$ and further concentration at about $2.5 \AA$ and $3.6 \AA$. Table 1 provides the numbers of neighbours and distances in a single layer of the graphite structure through
Table 1. Inter-atomic distances $(\AA)$ in a single layer of Ledo coal and graphite structure.

\begin{tabular}{lccc}
\hline $\begin{array}{l}\text { Ledo coal } \\
\text { distances }(\AA)\end{array}$ & $\begin{array}{c}\text { Number of } \\
\text { neighbours }\end{array}$ & $\begin{array}{c}\text { Graphite } \\
\text { distance }(\AA)\end{array}$ & $\begin{array}{c}\text { Number of } \\
\text { neighbours }\end{array}$ \\
\hline 0.4 & - & - & - \\
1.5 & 6 & 1.42 & 3 \\
2.5 & 12 & 2.46 & 6 \\
3.6 & 21 & 2.86 & 3 \\
4.6 & 33 & 3.75 & 6 \\
5.6 & 47 & 4.25 & 6 \\
6.6 & 64 & 4.92 & 6 \\
7.6 & 84 & 5.11 & 6 \\
\hline
\end{tabular}

the seventh coordination circle. It is observed that the position of the experimental maximum at $1.5 \AA$ is different from the first inter-atomic distance of graphite layer (1.42 $\AA$ ). From the G(r) curve, the function of radial distribution of atoms analysis (FRDA) indicates that the first maximum at $r=0.14 \mathrm{~nm}$ relates to the aliphatic $\mathrm{C}-\mathrm{C}$ bond (Type $\mathrm{C}-\mathrm{CH}=\mathrm{CH}-\mathrm{C}$ ), the second maximum at $r=0.25 \mathrm{~nm}$ relates to the distance between carbon atoms of aliphatic chains that are located across one carbon atom (Dunitz 1996). The curve intensity profiles obtained from FRDA show quite regular molecular packets for this coal.

The X-ray diffraction pattern of Ledo coal (figure 2) indicates that it is lignite in type. The pattern shows no evidence of graphite-like stacking of carbon layers. Absence of an inter-atomic distance of $1.42 \AA$ further indicates the absence of graphite-like arrangement in this coal. Grigoriew (1990) in his study of coal vitrinite with about the same chemical composition found no inter-atomic distance of $0.4 \AA$. This indicates that the $0.4 \AA$ distance comes from non-vitrinite portion of the 


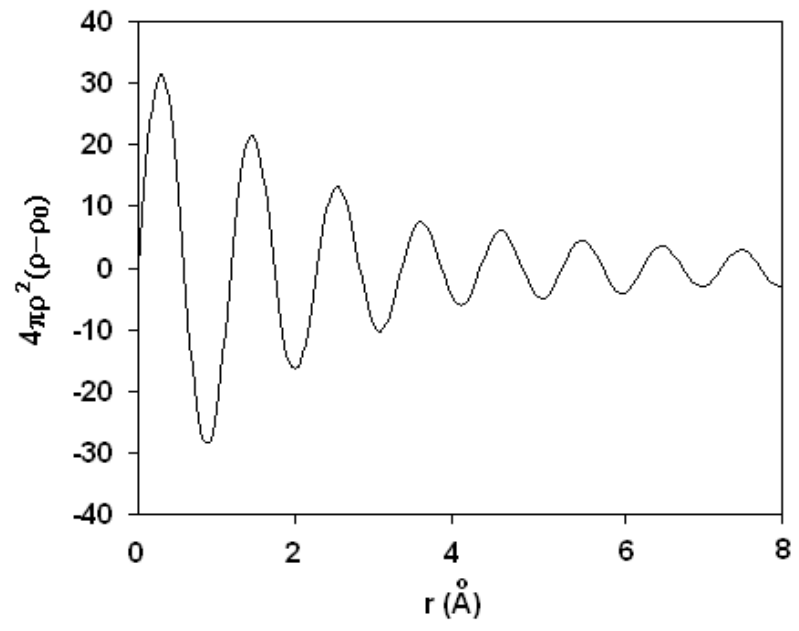

Figure 5. Plot for atomic pair distribution function of Ledo coal.

coal. Thus, the layers present in Ledo coal are also, not graphite-like in their internal co-ordination system. This can be also attributed to the average $\mathrm{C}-\mathrm{C}-\mathrm{C}$ valence angle. This angle may be estimated from the RDF by $\phi=\cos ^{-1}\left[p_{2}^{2}-2 p_{1}^{2}\right] / 2 p_{1}^{2}$. Using $p_{1}=0.4$ and $p_{2}=1.5, \phi$ is found to be greater than $180^{\circ}$ which does not seem to be realistic. Therefore, it may be concluded that Ledo coal is lignite in type and contains no evidence of graphite-like structure. This can be compared with the already reported lignite type of coal of different localities (Elliot 1981). However, the other RDF experimental maxima at the position 2.5, 3.6, 4.6, 5.6, 6.6 and $7.6 \AA$ shows some concentration of carbon atoms occurring in Ledo coal.

Figure 3 shows the FT-IR spectra of Ledo coal. In assigning the bands, the absorption bands are compared with the standard patterns (Grigoriew 1990; Karr 1978; Scheinman 1970; Speight 1994; Cooke et al 1986; Das 2001). A broad absorption band is observed at $3412 \mathrm{~cm}^{-1}$ in the coal, which appears to be mainly due to $\mathrm{N}-\mathrm{H}$ and $\mathrm{O}-\mathrm{H}$ groups. FT-IR spectra of Ledo coal further show that $\mathrm{O}-\mathrm{H}$ stretching vibrations are situated at 3853,3752 , 3622 and $3412 \mathrm{~cm}^{-1}$. The peaks for $\mathrm{O}-\mathrm{H}$ groups at $3600-3800 \mathrm{~cm}^{-1}$ appear to be for those associated with clay minerals. The aromatic hydrogen band at $3040 \mathrm{~cm}^{-1}$ is absent in the coal indicating its highly substituted and condensed nature. The peak at $2920 \mathrm{~cm}^{-1}$ and $2850 \mathrm{~cm}^{-1}$ appearing as sharp peaks of medium intensity, may be assigned to aliphatic and alicyclic $\mathrm{CH}_{3}, \mathrm{CH}_{2}$ and $\mathrm{CH}$ groups although the major contribution is expected to be due to $\mathrm{CH}_{2}$ groups. The intensity of peak at $2920 \mathrm{~cm}^{-1}$ is greater than the peak $2850 \mathrm{~cm}^{-1}$ indicating the presence of long aliphatic chains in the coal. The peak at $1699 \mathrm{~cm}^{-1}$ appears to indicate the presence of carbonyl $(\mathrm{C}=\mathrm{O})$ content. The peak around $1600 \mathrm{~cm}^{-1}$ in the coal is observed due to
Table 2. Physico-chemical characteristics of Ledo coal.

\begin{tabular}{lc}
\hline Parameters & Ledo coal \\
\hline Proximate analysis (wt\% as & received basis) \\
Moisture & 3.07 \\
Ash & 10.35 \\
Volatile matter & 43.38 \\
Fixed carbon & 43.20 \\
Forms of sulphur (wt\%) & \\
Total sulphur & 3.57 \\
Pyritic sulphur & 0.58 \\
Sulphate sulphur & 0.43 \\
Organic sulphur & 2.56 \\
Ultimate analysis (wt\% dry basis) \\
C & 72.60 \\
H & 5.33 \\
N & 0.92 \\
O (by difference) & 10.80 \\
\hline
\end{tabular}

aromatic $\mathrm{C}=\mathrm{C}$, vinylic $\mathrm{C}=\mathrm{C}$ and possibly due to other O-containing functional groups. The oxygen containing functional groups found in coal specifically include phenols and alcohols, ethers, carboxylic acid and carbonyls. In view of the diversity of decomposed plant matter, finding any systematic variation in the distribution of these functional groups in coal seems unlikely. Several authors have reviewed quantitative determination of these various oxygen functional groups.

A strong band at $1436 \mathrm{~cm}^{-1}$ in the coal was observed. This is mainly due to $\mathrm{CH}_{3}$ asymmetric deformation and $\mathrm{CH}_{2}$ group in bridges but may also be partly due to aromatic $\mathrm{C}=\mathrm{C}$ and strongly hydrogen bonded $\mathrm{O}-\mathrm{H}$ groups. The band at $1372 \mathrm{~cm}^{-1}$ is mainly due to $\mathrm{CH}_{3}$ symmetric deformation while $-\mathrm{CH}_{3}$ and $-\mathrm{CH}_{2}$ in cyclic structures may also partly contribute to this band. Intensity of this peak is much lower than the peak at $1436 \mathrm{~cm}^{-1}$ indicating that the methylene as long side chains. The band between $880 \mathrm{~cm}^{-1}$ and $750 \mathrm{~cm}^{-1}$ has been assigned to aromatic structures. The weak band at $690 \mathrm{~cm}^{-1}$ observed in the coal could possibly be due to $\mathrm{C}-\mathrm{S}$ bond. These absorptions are most useful in determining the aromatic ring structure of a coal.

Most of the peaks in FT-IR spectra of coal between 1100 and $400 \mathrm{~cm}^{-1}$ can be assigned to clay minerals such as quartz, kaolinite, illite and the montmorillonite group. The distinct peak at $1091 \mathrm{~cm}^{-1}, 1031 \mathrm{~cm}^{-1}, 1008 \mathrm{~cm}^{-1}$ and $471 \mathrm{~cm}^{-1}$ can be attributed to these mineral groups in Ledo coal sample. The $\mathrm{Si}-\mathrm{O}-\mathrm{Si}$ stretching vibration causes absorption at $1031 \mathrm{~cm}^{-1}$ and $1008 \mathrm{~cm}^{-1}$. The $\mathrm{Si}-\mathrm{O}$ bending vibration contributes to the strong absorption at 533 and $471 \mathrm{~cm}^{-1}$. Both these peaks can also be due to the presence of ionic sulphates. A weak absorption at $1163 \mathrm{~cm}^{-1}$ in the FT-IR of Ledo coal can be ascribed to the presence 
Table 3. Ash composition of the coal sample (wt\%).

\begin{tabular}{ccccccccc}
\hline Coal & $\mathrm{SiO}_{2}$ & $\mathrm{Fe}_{2} \mathrm{O}_{3}$ & $\mathrm{MgO}$ & $\mathrm{CaO}$ & $\mathrm{SO}_{3}$ & $\mathrm{TiO}_{2}$ & $\mathrm{Al}_{2} \mathrm{O}_{3}$ & Others \\
\hline Ledo & 63.1 & 9.7 & 0.7 & 1.1 & 0.5 & 0.5 & 23.6 & 0.8 \\
\hline
\end{tabular}

of mineral quartz. A weak absorption due to iron pyrite $\left(\mathrm{FeS}_{2}\right)$ at $420 \mathrm{~cm}^{-1}$ is also observed. A small but visible band at $692 \mathrm{~cm}^{-1}$ may possibly be due to magnetite $\left(\mathrm{Fe}_{2} \mathrm{O}_{3}\right)$. The FT-IR results were confirmed from $\mathrm{C}^{13} \mathrm{NMR}$ results, applied in the same type of samples (Iordanidis 2002). Baruah et al (2003) also observed the presence of $\mathrm{O}-\mathrm{H}$ stretching and $\mathrm{Si}-\mathrm{O}$ stretching/bending vibrations and quartz as the most abundant mineral in Tirap, Tikak and Baragolai coals of the same coalfield through FT-IR and XRD studies. Tables 2 and 3 show the physico-chemical properties of the coal sample. The carbon content of $72.60 \mathrm{wt} \%$ indicates it to be a highly carbonaceous material. This is also a high sulphur (3.57 wt\%) coal with $2.56 \mathrm{wt} \%$ organic sulphur. The ash composition of Ledo coal shows high silica content $(63.1 \mathrm{wt} \%)$ followed by $\mathrm{Al}_{2} \mathrm{O}_{3}$ and $\mathrm{Fe}_{2} \mathrm{O}_{3}$ with $23.6 \mathrm{wt} \%$ and $9.7 \mathrm{wt} \%$, respectively.

\section{Conclusion}

Ledo coal is amorphous in nature. FRDA indicates that it is lignite in type and there is no evidence of graphite-like structure. The first maximum in FRDA at $r=0.14 \mathrm{~nm}$ relates to the aliphatic $\mathrm{C}-\mathrm{C}$ bond (Type $\mathrm{C}-\mathrm{CH}=\mathrm{CH}-\mathrm{C}$ ), the second maximum at $r=0.25 \mathrm{~nm}$ relates to the distance between carbon atoms of aliphatic chains that are located across one carbon atom. The curve intensity profiles obtained from FRDA show quite regular molecular packets for this coal. FT-IR study shows the presence of aliphatic $-\mathrm{CH},-\mathrm{CH}_{2}$ and $-\mathrm{CH}_{3}$ groups, aliphatic $\mathrm{C}-\mathrm{O}-\mathrm{C}$ stretching associated with $-\mathrm{OH}$ and $-\mathrm{NH}$ stretching vibrations and HCC rocking (single and condensed rings).

\section{Acknowledgements}

We are thankful to Northeast coalfield, Margherita for supplying the coal sample and the Director,
RRL - Jorhat for allowing us to publish this paper. The comments and suggestions received from the two anonymous reviewers are gratefully acknowledged. One author (BKS) is also thankful to Prof. S Bhattacharya, Indian School of Mines, University, Dhanbad and Mr B P Baruah, Senior Scientist, RRL - Jorhat for their help in different ways.

\section{References}

Baruah M K, Kotoky P and Borah G C 2003 Distribution and nature of organic/mineral bound elements in Assam coals, India; Fuel 821783.

Cooke N E, Fuller M O and Gaikwad R P 1986 FT-i.r. spectroscopic analysis of coals and coal extracts; Fuel 65(9) 1254.

Das T K 2001 Evolution characteristics of gases during pyrolysis of maceral concentrates of Russian coking coals; Fuel 80 489-500.

Dunitz Jack D 1996 X-ray analysis and the structure of organic molecules, $2^{\text {nd }}$ Edition, Helvetica Chimica Acta 338.

Elliot Martin A (ed.) 1981 Chemistry of coal utilization, 2nd supplementary volume (New York: John Wiley \& Sons) 89.

Grigoriew H 1990 Diffraction studies of coal structure; Fuel 6984.

Iordanidis A 2002 Organic Geochemistry and Petrology of Amynled Lignites, PhD Thesis, Aristotle University of the Ssaloniki, Greece.

Karr Jr C 1978 Analytical Methods for Coal and Coal products (New York: Academic Press) Vol. II.

Klug P H and Alexander L E 1974 X-ray diffraction procedures (New York: John Wiley \& Sons).

Kruh R F 1962 Diffraction studies of the structure of Liquids; Chem. Rev. 62319.

Misra B K 1992 Optical properties of some tertiary coals from northeastern India: their depositional environment and hydrocarbon potential; Int. J. Coal Geol. 20(1-2) $115-144$

Scheinman F 1970 An introduction to spectroscopic methods for the identification of organic compounds (Oxford: Pergamon Press) Vol. 1.

Speight J G 1994 Application of Spectroscopic Techniques to the Structural Analysis of Coal; Applied Spectroscopy Reviews 29(2) 117. 